\title{
Carmen M. MANGION, Contested Identities. Catholic Women Religious in Nineteenth-Century England and Wales
}

Manchester - New York, Manchester University Press, 2008, XIV + 282 p.

Jean-Louis Ormières

\section{(2) OpenEdition}

Journals

Édition électronique

URL : http://journals.openedition.org/assr/22067

DOI : $10.4000 /$ assr.22067

ISSN : $1777-5825$

Éditeur

Éditions de l'EHESS

Édition imprimée

Date de publication : 31 décembre 2010

Pagination : 9-242

ISBN : 9782713223013

ISSN : 0335-5985

Référence électronique

Jean-Louis Ormières, " Carmen M. mangIon, Contested Identities. Catholic Women Religious in

Nineteenth-Century England and Wales », Archives de sciences sociales des religions [En ligne], 152 |

octobre-décembre 2010, document 152-82, mis en ligne le 12 mai 2011, consulté le 21 septembre 2020. URL : http://journals.openedition.org/assr/22067 ; DOI : https://doi.org/10.4000/assr.22067

Ce document a été généré automatiquement le 21 septembre 2020.

(C) Archives de sciences sociales des religions 


\section{Carmen M. MANGION, Contested Identities. Catholic Women Religious in Nineteenth-Century England and Wales}

Manchester - New York, Manchester University Press, 2008, XIV + 282 p.

Jean-Louis Ormières

\section{RÉFÉRENCE}

Carmen M. MANGION, Contested Identities. Catholic Women Religious in NineteenthCentury England and Wales, Manchester - New York, Manchester University Press, 2008, XIV $+282 p$.

1 Le livre important que Carmen M. Mangion consacre aux congrégations religieuses féminines en Angleterre et dans le Pays de Galle au XIX ${ }^{\mathrm{e}}$ siècle témoigne de l'intérêt que suscite chez les chercheurs d'outre-Manche une religion pourtant minoritaire. C.M. Mangion vient en effet alimenter un domaine de recherche - les femmes religieuses en plein essor depuis le début des années quatre-vingt.

2 S'appuyant sur les archives d'une dizaine de congrégations, d'une part, et d'autre part sur de nombreux recensements, des rapports diocésains, des textes ou des périodiques contemporains, elle utilise l'approche prosoprographique pour appréhender ces congrégations et les identités individuelles des religieuses qui les composent. L'analyse prosopographique des congrégations étudiées permet de faire apparaître les similitudes et les différences et de montrer de quelle manière l'affiliation à ces congrégations a pu façonner et contraindre l'identité individuelle de ces religieuses. L'interaction entre la religieuse et sa congrégation et l'influence de l'environnement culturel façonnaient leur identité individuelle. Les identités de ces femmes religieuses sont ici examinées sous l'angle à la fois du genre, de l'ethnicité et du milieu social. 
3 Consacrée à l'évolution de ces identités, la première partie de l'ouvrage comprend trois chapitres. Le premier traite de l'évolution de la vie religieuse en Angleterre. La forte progression des congrégations féminines, tout au long du siècle, témoigne du dynamisme de la vie religieuse et de l'attrait qu'elle exerce sur un grand nombre de femmes.

4 Le deuxième chapitre s'attache à démêler ce qui pouvait conduire ces femmes à entrer dans ces communautés. Ce choix n'était nullement passif, souligne C.M. Mangion, qui rejette, comme nombre d'historiens, le mythe persistant d'une femme victorienne «oisive et innocente». Ces femmes étaient attirées par ce qu'elles considéraient comme les avantages de la vie religieuse. Elles faisaient le choix qui correspondait le mieux à leurs besoins personnels, spirituels, économiques et à leur vocation.

5 Le troisième chapitre montre comment la formation de la vie au sein de la congrégation façonne leur identité de femme religieuse. Le postulat, comme le noviciat, faisait figure de rite de passage permettant de tester la vocation de chacune et son aptitude à se joindre à la communauté de son choix.

6 Dans la seconde partie du livre, C.M. Mangion s'attache à décrire les activités de ces religieuses qu'il s'agisse de leur contribution à l'évangélisation (chap.4), qu'elle juge sous-estimée, ou de leur activité professionnelle proprement dite dans le domaine de l'éducation, dans les hôpitaux ou dans les services sociaux (chap.5).

7 En dépit de leur nombre, somme toute très modeste (on compte alors au mieux dix mille religieuses catholiques dans le pays), ces femmes auraient, selon l'auteure, grandement contribué à la consolidation de la culture catholique au $\mathrm{xIx}^{\mathrm{e}}$ siècle en préparant jeunes et moins jeunes aux sacrements de l'Église catholique.

Le rôle missionnaire des religieuses et leur identité professionnelle étaient inextricablement liés à leur activité dans les trois domaines mentionnés ci-dessus et en particulier à l'instruction des enfants à laquelle participent soixante-dix pour cent des congréganistes femmes d'Angleterre et du Pays de Galles à la fin du xix siècle. Travaillant pour l'essentiel au niveau primaire au milieu du siècle, elles vont peu à peu également se consacrer à l'instruction au niveau secondaire. Avec la professionnalisation de l'enseignement, les congrégations encouragent les sœurs à l'obtention de diplôme. Reste que l'enseignement était un moyen et non une fin, celle-ci demeurant centrée sur l'évangélisation. Quoi qu'il en soit, C.M. Mangion en conclut que ce fut le couplage de cette identité professionnelle et de cette identité religieuse qui a contribué à faire accepter la femme religieuse dans la sphère publique et dans la conscience protestante.

9 L'auteure montre comment ces congrégations féminines utilisent la métaphore de la famille si prégnante dans l'Angleterre victorienne pour façonner les comportements et les attitudes de ses membres et aboutissent à la construction d'une véritable identité collective (chap.6). Mais ce sentiment d'appartenance collective ne parvient pourtant pas à faire disparaître les différences de classe et d'«ethnicité», près de la moitié de ces sœurs étant d'origine irlandaise (chap.7). Autant de différences qui se révèlent, le contraire eut été étonnant, décisives pour l'attribution de la place de ces religieuses au sein de la congrégation. Reste que ces congrégations ont permis à leurs membres de s'exercer à l'autorité (exercice habituellement réservé aux seuls hommes) au sein des couvents, comme dans les institutions qu'elles dirigeaient dans la sphère publique (école, hôpitaux). 
10 En définitive, tout en se conformant au modèle victorien de la féminité, ces congrégationnistes, vivaient dans un espace (le couvent) où la femme exerçait pleinement son leader-ship et le pouvoir. Insidieusement, les congrégations remettaient en cause les valeurs dominantes en créant un mode de vie alternatif où la femme avait un rôle central.

11 Compte tenu de l'indéniable qualité de l'ouvrage, on peut s'étonner néanmoins que son auteure ait laissé passer des bévues comme celle où il est fait référence à la spiritualité de Simon de Montfort alors qu'il s'agissait en réalité de Grignon de Montfort (p.104).

12 Ce livre n'est pas seulement utile pour une meilleure appréhension de la vie et des activités des religieuses, il éclaire également la situation et le rôle du genre féminin dans le domaine public comme dans le domaine privé. Il contribue de fait à une histoire plus générale de la transformation de la société anglaise à laquelle les femmes ont pris une part active. Que leur domaine de recherche soit l'histoire religieuse, l'histoire du genre, l'histoire culturelle ou encore l'histoire sociale, étudiants et chercheurs devraient pouvoir tirer grand profit à la lecture de ce livre. 